\title{
ANÁLISE DA APLICAÇÃO DO PROGRAMA MUNICÍPIO VERDEAZUL (PMVA) NOS MUNICÍPIOS DA BACIA DO RIO CORUMBATAÍ.
}

\author{
Heloísa N.Oliveira*, Luciana C. S. Fernandes.
}

\section{Resumo}

Este artigo tem por objetivo analisar o desenvolvimento do PMVA em 7 dos 8 municípios pertencentes à Bacia do Rio Corumbataí com a finalidade de complementar as informações e dados coletados para subsidiar o Projeto Geoparque Corumbataí (http://geoparkcorumbatai.com.br) através de propostas de ações estratégicas tais como: Crescimento em pontuação dentro do PMVA, e os benefícios que este oferece, disseminação de conhecimento sobre sustentabilidade e melhorias na gestão ambiental. Foram utilizados como método de pesquisa bases legais brasileiras, bibliografias disponíveis, casos de sucesso conhecidos, dados fornecidos pelo Programa e contato com as Secretarias responsáveis em cada município, com isto foi possível verificar benefícios na implantação do geoparque e PMVA para o turismo que, consequentemente, subsidia a gestão ambiental municipal.

\section{Palavras-chave:}

Desenvolvimento sustentável; Pontuações; Geoparque.

\section{Introdução}

Foram analisados os contextos turísticos, geológicos e socioambientais de 7 municípios pertencentes a Bacia do Rio Corumbataí, bem como suas atuações no PMVA. Com isto objetivou-se a identificação de possíveis melhorias nas ações desenvolvidas para o PMVA que, consecutivamente, colaborassem para o reconhecimento de um geoparque na região pela UNESCO.

\section{Resultados e Discussão}

Foram utilizadas as bases de dados disponibilizadas pelo PMVA para a construção das análises do desempenho de cada município bem como o envio de questionários individuais a cada interlocutor.

Como pode ser observado pelo Gráfico 1 abaixo, as pontuações alcançadas pelos municípios analisados nos anos de 2017 e 2018, demonstram nítido avanço de forma geral.

Gráfico 1. Pontuação dos municípios no PMVA de 2017 à $2018^{1}$.

Pontuações do municípios em 2017 e 2018

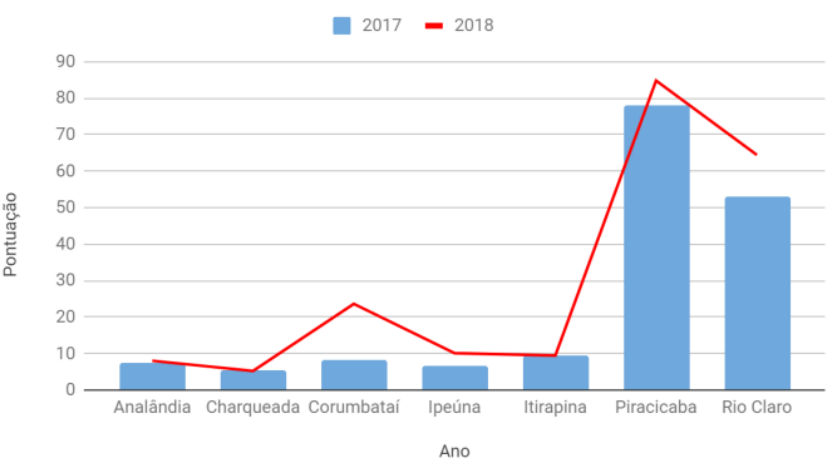

No entanto, somente esta análise superficial não foi suficiente para o entendimento completo, razão pela qual optou-se por uma análise mais complexa das diretivas em cada município, conforme exemplificado pelo Gráfico 2, abaixo.

Gráfico 2. Pontuação de cada diretiva nos anos de 2017 e 2018 do município de Piracicaba ${ }^{1}$

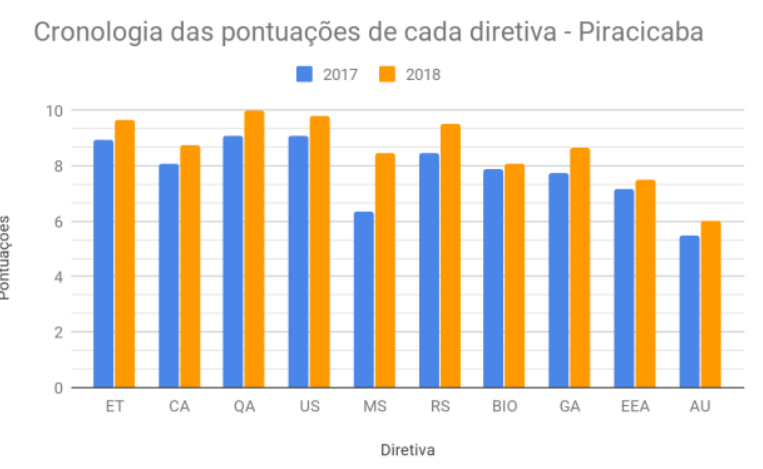

A partir da análise dos dados quantitativos, juntamente com o retorno de alguns questionários, foi possível propor sugestões de melhoria dentro do PMVA para os municípios, tais como:

- Participação mais ativa da gestão;

- Valorização das boas práticas;

- Elaboração de Planos e especial envolvendo turismo;

- Uso de ferramentas online.

\section{Conclusões}

A região estudada possui enorme potencial turístico, porém sem muita exploração. Diante disto, a participação no PMVA associada a criação e implantação de um geoparque na região possibilitam um planejamento socioambiental mais efetivo, culminando em maior atratividade turística e geração de renda, como no caso do Geoparque Araripe ${ }^{2}$.

\section{Agradecimentos}

Gostaria de agradecer a UNICAMP e ao PIBIC/CNPq por me darem a oportunidade de aprimorar ainda mais o meu conhecimento. Gostaria também de agradecer a minha orientadora, Luciana Fernandes, pela orientação em todo o projeto.

${ }^{1}$ MUNICÍPIO VERDEAZUL. Pontuações. Disponível em: $<$ http://verdeazuldigital.sp.gov.br/site/pontuacoes/>. Acesso em janeiro de 2019.

${ }^{2}$ FERNANDES, L.C.S. Breves considerações sobre a certificação da Bacia Hidrográfica do Corumbataí como Geopark UNESCO. EDUCAÇÃO AMBIENTAL: A SUSTENTABILIDADE DOS AMBIENTES RURAIS E URBANOS/Giovanni Seabra (Organizador). Ituiutaba: Barlavento, 2017. $1.255 \mathrm{p}$. 